\title{
Fetal nuchal translucency: ultrasound screening for chromosomal defects in first trimester of pregnancy
}

\author{
K H Nicolaides, G Azar, D Byrne, C Mansur, K Marks
}

Abstract

Objective-To examine the significance of fetal nuchal translucency at 10-14 weeks' gestation in the prediction of abnormal fetal karyotype.

Design-Prospective screening study.

Setting-The Harris Birthright Research Centre for Fetal Medicine, King's College Hospital, London.

Subjects -827 fetuses undergoing first trimester karyotyping by aminocentesis or chorionic villus sampling.

Main outcome measure-Incidence of chromosomal defects.

Results - The incidence of chromosomal defects was $3 \%$ ( 28 of 827 cases). In the $51(6 \%)$ fetuses with nuchal translucency 3-8 $\mathrm{mm}$ thick the incidence of chromosomal defects was $35 \%$ (18 cases). In contrast, only 10 of the remaining $776(1 \%)$ fetuses were chromosomally abnormal.

Conclusion-Fetal nuchal translucency $\geqslant 3 \mathrm{~mm}$ is a useful first trimester marker for fetal chromosomal abnormalities.

\section{Introduction}

In the second and third trimesters of pregnancy there is a high association between fetal nuchal cystic hygromas or nuchal oedema and chromosomal abnormalities (table I). ${ }^{12}$ This ultrasound screening study examines the possible significance of abnormal nuchal fluid in the first trimester as a marker of chromosomal abnormalities.

\section{Patients and methods}

During 22 months (January 1990 to October 1991) 827 women with viable pregnancies were referred to our centre for first trimester fetal karyotyping because of advanced maternal age, parental anxiety, or a family history of a chromosomal abnormality in the absence of balanced parental translocation. The median maternal

Harris Birthright Research Centre for Fetal Medicine, King's College Hospital Medical School, London SE5 8RX

K H Nicolaides, director

$\mathrm{G}$ Azar, research fellow

D Byrne, research fellow

C Mansur, research fellow

$\mathrm{K}$ Marks, cytogeneticist

Correspondence to: $\mathrm{Mr}$ Nicolaides.

$B M f$ 1992;304:867-9
TABLE I - Relation of chromosomal abnormalities and nuchal oedema or nuchal cystic hygromas in second and third trimester fetuses. ${ }^{\prime 2}$ Figures are numbers (percentages) of fetuses

\begin{tabular}{|c|c|c|}
\hline & Nuchal oedema & $\begin{array}{c}\text { Nuchal cystic } \\
\text { hygromas }\end{array}$ \\
\hline No of fetuses & 145 & 44 \\
\hline Abnormal karyotype & $52(36)$ & $33(75)$ \\
\hline Trisomy 13 & $6(11)$ & \\
\hline Trisomy 18 & $5(10)$ & $1(3)$ \\
\hline Trisomy 21 & $30(57)$ & $1(3)$ \\
\hline Trisomy $21 \mathrm{q}$ & $1(2)$ & \\
\hline Trisomy $4 \mathrm{q}$ & $1(2)$ & \\
\hline Translocation 14,15 & $1(2)$ & \\
\hline Deletion $4 p$ & $1(2)$ & \\
\hline Deletion 5q & $1(2)$ & \\
\hline Deletion $14 \mathrm{q}$ & $1(2)$ & \\
\hline Turner's & $3(6)$ & $31(94)$ \\
\hline Triploidy & $2(4)$ & \\
\hline
\end{tabular}

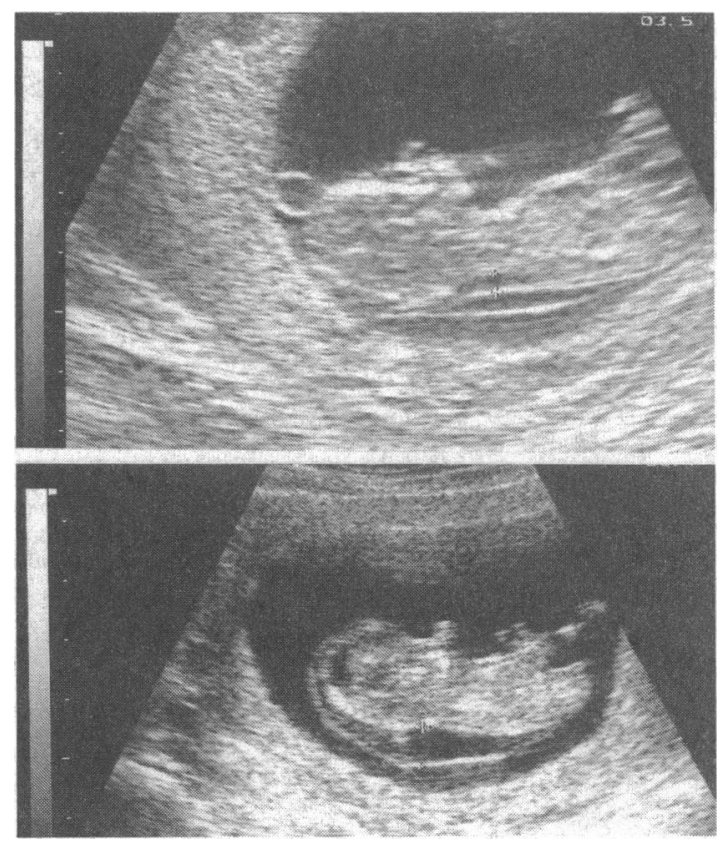

Ultrasomic appearances of subcutaneous nuchal translucency. Both skin and amnion appear as thin membranes (top). In some cases translucency extends over wide area of fetus but is most prominent behind neck (bottom)

age was 38 years (range 22-47). Gestational age, calculated from the last menstrual period and confirmed by measuring the fetal crown-rump length, was 10-14 (mean 11) weeks.

Transabdominal ultrasound examination (curvilinear $5 \mathrm{MHz}$ transducer; Aloka $650 \mathrm{CO}$ Limited, Tokyo) was performed to obtain a sagittal section of the fetus for measuring crown-rump length and the maximum thickness of the subcutaneous translucency between the skin and the soft tissue overlying the cervical spine (figure). Care was taken to distinguish between fetal skin and amnion because at this gestation both structures appear as thin membranes.

The mothers gave written informed consent to our ongoing randomised trial comparing safety and diagnostic accuracy of early amniocentesis with chorionic villus sampling. ${ }^{3}$ In this trial both procedures are performed transabdominally by the ultrasound guided use of a 20 gauge needle; amniocentesis was performed in 433 cases and chorionic villus sampling in 394.

\section{Results}

The fetal karyotype was normal in 799 cases and abnormal in 28 (3\%; trisomy 13, two cases; trisomy 18 , five; trisomy 21,13 ; trisomy 22 , one; $47, \mathrm{XY}+$ fragment, one; $47, \mathrm{XX}+21 / 46, \mathrm{XX}$, one; $47, \mathrm{XX}+8 /$ $46, \mathrm{XX}$, one; $47, \mathrm{XXX} / 46, \mathrm{XX}$, one; $47, \mathrm{XXX}$, one; $47, X X Y$, two $)$. All three cases of mosaicism were from 
chorionic villus sampling, but they were subsequently confirmed (by amniocentesis or cordocentesis) to be true fetal mosaics. Additionally, in the chorionic villus sampling group there was a case of confined placental mosaicism (trisomy 2 ). ${ }^{3}$

In the $51(6 \%)$ fetuses with nuchal translucency 3$8 \mathrm{~mm}$ thick the incidence of chromosomal defects was $35 \%$ (18 cases). In contrast, only 10 of the remaining $776(1 \%)$ fetuses were chromosomally abnormal (table II). In this group of 776 fetuses there were 52 with nuchal translucency $1-2 \mathrm{~mm}$ thick, and none of these were chromosomally abnormal. The maternal age related incidence of fetal chromosomal defects in the presence or absence of fetal nuchal translucency of $3 \mathrm{~mm}$ or more is shown in table III.

TABLE II-Relation of fetal nuchal translucency and abnormal karyotype in 827 low risk pregnancies at 10-14 weeks' gestation

\begin{tabular}{|c|c|c|c|c|c|c|c|c|c|c|}
\hline \multirow{2}{*}{$\begin{array}{l}\text { Nuchal } \\
\text { thickness } \\
\text { (mm) }\end{array}$} & \multirow{2}{*}{$\begin{array}{l}\text { Total } \\
\text { fetuses }\end{array}$} & \multicolumn{9}{|c|}{ Abnormal karyotype } \\
\hline & & No $(\%)$ of fetuses & $\operatorname{Tr} 13$ & $\operatorname{Tr} 18$ & $\operatorname{Tr} 21$ & $\operatorname{Tr} 22$ & Trf & $47, X X Y$ & $47, \mathrm{XXX}$ & Mosaic \\
\hline$<1$ & 724 & $10(1)$ & & 1 & 3 & & & 2 & 1 & 3 \\
\hline $1-2$ & 52 & 0 & & & & & & & & \\
\hline 3 & 28 & $4(14)$ & 1 & & 1 & 1 & 1 & & & \\
\hline 4 & 12 & $6(50)$ & 1 & 1 & 4 & & & & & \\
\hline 5 & 6 & $4^{\star}(67)$ & & & 4 & & & & & \\
\hline 6 & 2 & $1+(50)$ & & 1 & & & & & & \\
\hline 7 & 2 & $2(100)$ & & 2 & & & & & & \\
\hline 8 & 1 & $1(100)$ & & & 1 & & & & & \\
\hline
\end{tabular}

$\star$ One of the two fetuses with normal karyotype had a major cardiac defect.

the one case with normal fetal karyotype had defects due to amnion disruption.

TABLE III-Incidence of chromosomal abnormalities in relation to maternal age (years) and presence or absence of nuchal translucency $\geqslant 3 \mathrm{~mm}$ thick. Figures are numbers (percentages) of fetuses

\begin{tabular}{lccc}
\hline & & \multicolumn{2}{c}{ Nuchal translucency } \\
\cline { 3 - 4 } $\begin{array}{l}\text { Maternal age } \\
\text { (years) }\end{array}$ & Total & Absent & Present \\
\hline $22-23$ & $0 / 3$ & $0 / 2$ & $0 / 1$ \\
$24-25$ & $0 / 5$ & $0 / 5$ & $0 / 0$ \\
$26-27$ & $0 / 5$ & $0 / 5$ & $0 / 0$ \\
$28-29$ & $0 / 8$ & $0 / 8$ & $0 / 0$ \\
$30-31$ & $0 / 19$ & $0 / 19$ & $0 / 0$ \\
$32-33$ & $0 / 27$ & $0 / 27$ & $0 / 0$ \\
$34-35$ & $2 / 87(2)$ & $0 / 81$ & $2 / 6(33)$ \\
$36-37$ & $3 / 222(1)$ & $1 / 213(0)$ & $2 / 9(22)$ \\
$38-39$ & $7 / 242(3)$ & $2 / 228(1)$ & $5 / 14(36)$ \\
$40-41$ & $6 / 119(5)$ & $3 / 111(3)$ & $3 / 8(38)$ \\
$42-43$ & $7 / 73(10)$ & $3 / 64(5)$ & $4 / 9(44)$ \\
$44-45$ & $2 / 14(14)$ & $0 / 10$ & $2 / 4(50)$ \\
$46-47$ & $1 / 3(33)$ & $1 / 3(33)$ & $0 / 0$ \\
\hline Total & $28 / 827(3)$ & $10 / 776(1)$ & $18 / 51(35)$ \\
\hline
\end{tabular}

Follow up ultrasound exminations in the fetuses with nuchal translucency showed resolution of the fluid by 20 weeks' gestation in all 52 fetuses with translucency 1-2 mm thick and in 31 of the 33 chromosomally normal fetuses with translucency of $3-8 \mathrm{~mm}$. In the 18 cases with chromosomal defects the pregnancies were aborted at the request of the parents. In one of the fetuses with persistent oedema echocardiography detected a univentricular heart, and the diagnosis was confirmed at postmortem examination after termination of the pregnancy. In another case amnion disruption sequence was suspected at the original ultrasound examination at 11 weeks because the amniotic membrane was closely applied to the fetus and all amniotic fluid was in the extra-amniotic cavity; the nuchal translucency was $6 \mathrm{~mm}$. The diagnosis was subsequently confirmed by follow up scans showing bilateral talipes and amputation deformities of the left hand.

\section{Discussion}

This prospective screening study of women undergoing fetal karyotyping for low risk indications has established four main facts. Firstly, the incidence of fetal nuchal translucency of $3 \mathrm{~mm}$ or more detected by transabdominal ultrasonography at 10-14 weeks' gestation is $6 \%$. Secondly, the presence of fetal nuchal translucency is associated with a more than 10-fold increase and the absence of translucency with a threefold decrease in risk for chromosomal abnormality. Thirdly, the risk of chromosomal abnormalities increases with the thickness of the nuchal translucency (in this series, however, numbers were too small for accurate calculation of risks). And, finally, the pattern of associated chromosomal defects, trisomies rather than Turner's syndrome, is similar to that observed in second trimester fetuses with nuchal oedema rather than with cystic hygromas.

In second trimester fetuses with pathological accumulation of fluid in the nuchal region there is a difference between cystic hygromas and oedema both in terms of pathogenesis and in terms of their association with different chromosomal defects (table I) and genetic disorders. ${ }^{12}$ Thus cystic hygromas (bilateral, septated, cystic structures) are strongly associated with Turner's syndrome and are thought to represent overdistension of the jugular lymphatic sacs as a consequence of failure of communication with the internal jugular vein. ${ }^{14}$ In contrast, nuchal oedema is due to subcutaneous accumulation of fluid and may be considered as an early sign of hydrops fetalis, which has a diverse aetiology, including trisomies, cardiovascular and pulmonary defects, skeletal dysplasias, congenital infection, and metabolic and haematological disorders. ${ }^{25}$

Previous publications on first trimester nuchal fluid are mainly confined to a few case reports in which the underlying lesion is referred to as "cystic hygromas." Although in some studies the condition is clearly defined as multiseptated thin walled cystic mass similar to that seen in the second trimester, in others the term is used loosely to include nuchal thickening or oedema. Bronshtein et al, in a study of eight fetuses with "cystic hygromas" diagnosed at 9-15 weeks' gestation, classified the lesions into septated and non-septated types. They suggested that the former are associated with chromosomal defects or fetal death whereas fetuses with non-septated hygromas are chromosomally normal and often have a good outcome. "In contrast, Cullen et al examined 29 fetuses with "cystic hygromas" at 10-13 weeks and reported that neither the incidence of chromosomal defects nor the prognosis could be predicted by the ultrasonic appearance of the lesion (septated and non-septated, posterior or lateral cervical, with or without hydrops). ${ }^{12}$

\section{TRANSLUCENCY, MORE ACCURATE TERM}

In the present study the term translucency, rather than nuchal oedema or cystic hygromas, is used because this was the ultrasonic feature that was observed. The chromosomally abnormal fetuses were not amenable to detailed postmortem examination as first trimester suction termination was performed and therefore the underlying pathology of the nuchal lesion could not be ascertained. Similarly, no histological investigations could be undertaken in the chromosomally normal group because in all but two of the fetuses the translucency disappeared by 20 weeks' gestation. Although in the chromosomally abnormal group the natural course of the nuchal translucencies could not be defined, as the pregnancies were terminated, it could be postulated on the basis of the type of associated chromosomal defects that the translucencies were more likely to have evolved into nuchal oedema rather than cystic hygromas.

The sensitivity and specificity of nuchal translucency as a marker of chromosomal defects in routine transabdominal ultrasound examination of the whole population remains to be determined. Nevertheless, 
patients currently requesting fetal karyotyping can be counselled in favour of early testing if nuchal translucency is present as their risk is dramatically increased. Those without fetal nuchal translucency can be counselled that their background risk is reduced and consequently that they may prefer to have later amniocentesis, which may be safer, or to avoid invasive testing altogether.

1 Azar GB, Snijders RJM, Gosden C, Nicolaides KH. Fetal nuchal cystic hygromata: associated malformations and chromosomal defects. Fetal Diagn Ther. In press.

2 Nicolaides KH, Azar GB, Snijders RJM, Gosden C. Fetal nuchal edema: associated malformations and chromosomal defects. Fetal Diagn Ther. In press.

3 Byrne D, Marks K, Azar G, Nicolaides K. Randomized study of early amniocentesis versus chorionic villus sampling at 10-13 weeks' gestation: technical and cytogenic comparison of 650 patients. Ultrasound in Obstetrics and Gynecology 1991;1:234-40.

4 Van der Putte SCJ. Lymphatic malformation in human fetuses. Virchows Arch [A] 1977;376:233-46.

Nicolaides KH, Rodeck CH, Lange I, Watson J, Gosden CM, Miller D, et al.
Fynaecol 1985;92:671-9.

6 Gustavii B, Edvall $\mathrm{H}$. First-trimester diagnosis of cystic nuchal hygroma. Acta Obstet Gynecol Scand 1984;63:377-8.

7 Dallapiccola B, Zelante L, Perla G, Villani G. Prenatal diagnosis of recurrence of cystic hygroma with normal chromosomes. Prenat Diagn 1984;4:383-6.

8 Reuss A, Pijpers L, Schampers PTFM, Wladimiroff JW, Sachs ES. The importance of thorionic villus sampling after first trimester diagnosis of importance of thorionic villus sampling after
cystic hygroma. Prenat Diagn 1987;7:299-301.

9 Reuss A, Pijpers L, van Swaaij E, Jahoda MGJ, Wladimiroff JW. Firsttrimester diagnosis of recurrence of cystic hygroma using a transvaginal ultrasound transducer. Case report. Eur $\mathcal{f}$ Obstet Gynecol Reprod Biol 1987;26:271-3.

10 Pons JC, Diallo AA, Eydoux P, Rais S, Doumerc S, Frydman R, Papiernik E. Chorionic villus sampling after first trimester diagnosis of fetal cystic hygroma colli. Eur f Obstet Gynecol Reprod Biol 1989;33:141-6.

11 Bronshtein $M$, Rottem S, Yoffe N, Blumenfeld Z. First trimester and early second trimester diagnosis of nuchal cystic hygroma by transvaginal sonography: diverse prognosis of the septated from the non-septated lesion. Am F Obstet Gynecol 1989;161:78-82.

12 Cullen MT, Gabrielli S, Green JJ, Rizzo N, Mahoney MJ, Salafia C, et al. Diagnosis and significance of cystic hygroma in the first trimester. Prenat Diagn 1990;10:643-51.

(Accepted 13 fanuary 1992)

\title{
Predictive diagnosis of familial adenomatous polyposis with linked DNA markers: population based study
}

\author{
F MacDonald, D G Morton, P M Rindl, J Haydon, R Cullen, J Gibson, J P Neoptolemos, \\ M R B Keighley, C M McKeown, M Hultén
}

\section{Abstract}

Objectives - To evaluate the use of polymorphic DNA probes linked to the APC gene in the presymptomatic diagnosis of familial adenomatous polyposis.

Design-Four DNA probes were tested on an unselected population of patients at risk of familial adenomatous polyposis.

Subjects-The first 47 families notified to the West Midlands familial adenomatous polyposis register. Plus five families sent to our hospital as part of the West of Britain DNA consortium.

Main outcome measures-The proportion of families and family members in whom DNA testing could be used to adjust the estimate of risk.

Results - Only 17 families on the register (containing $46 \%(74 / 162)$ of the population at risk) had a suitable pedigree structure for DNA analysis. DNA was analysed in 12 of these families plus the five families from the West of Britain consortium. At least one probe was informative in 27 of the 33 subjects born with $50 \%$ risk, but the most informative probe $(\pi 227)$ was the one with the highest recombination rate $(10 \%)$. Flanking markers were informative in only four of the 33 subjects.

Conclusions - These findings confirm the potential for accurate predictive diagnosis of familial adenomatous polyposis with polymorphic DNA probes, but such an approach is currently limited to about one third of affected families. A combined approach to presymptomatic diagnosis, which includes DNA testing and indirect ophthalmoscopy, is advocated.

\section{Introduction}

Familial adenomatous polyposis is an autosomal dominant condition which shows almost complete penetrance and occurs at a frequency of 1:10000 births. ${ }^{1}$ Up to $40 \%$ of cases are new mutations. ${ }^{2}$ The condition is characterised by the presence of hundreds or even thousands of adenomatous polyps throughout the colon and rectum, at least one of which is certain to progress to malignancy. ${ }^{3}$ Children of affected people are at $50 \%$ risk of inheriting the defective gene and developing the condition. As the age of onset of colonic polyps is variable it is recommended that people at risk are screened by repeated bowel examination from puberty until at least 40 years of age. ${ }^{2}$

A predictive test that is informative before the development of polyps could improve surveillance of those at high risk and reduce the frequency of, or eventually eliminate the need for, bowel examination in those at low risk. Such tests include indirect ophthalmoscopy to detect the presence of congenital hypertrophy of the retinal pigment epithelium ${ }^{4}$ or a DNA based test using markers linked to the causative gene (APC).

After a cytogenetically detectable deletion in chromosome 5 was observed in a mentally retarded man with familial adenomatous polyposis, the disease was mapped to $5 \mathrm{q} 21-22$ by the polymorphic marker C11p11.56 Several other polymorphic markers, including $\pi 227$ and YN5.48, have subsequently been identified $^{78}$ and a high resolution map identifying the position of these and other markers relative to the APC gene, has been described. ${ }^{9}$

The potential of these markers for diagnosis of familial adenomatous polyposis before symptoms emerge has been shown, but their clinical value was limited. $\mathrm{C} 11 \mathrm{p} 11$ was relatively uninformative because one of the two alleles recognised by the probe was rare in the population. By contrast, $\pi 227$ was highly polymorphic but its use was limited because of its relatively high recombination rate. Recombination occurs due to crossing over of homologous chromosomes during meiosis, and the recombination rate of two markers is a measure of the genetic distance between them. In the case of $\pi 277$ this is $10 \%$. YN5.48 was the first linked marker to be localised to the telomeric side of the APC gene. ${ }^{10}$ This meant that the accuracy of diagnosis could be increased to close to $100 \%$ if both YN5.48 and one of the markers on the centromeric side of the gene were informative. When markers exist on both sides of the gene (flanking markers) inheritance can be highly accurately predicted as the occurrence of a recombination event can be positively identified in a patient in whom both markers are informative. 